\title{
Silent Brain Tuberculomas with Acute Miliary Tuberculosis in 13-Year Old Girl - Case Report
}

\author{
Hajric Zidan Zlata ${ }^{1}$, Pasic Amela ${ }^{2}$, Selimovic Selma ${ }^{2}$, Spahic Razija ${ }^{2}$ \\ ${ }^{1}$ Children's Department, General Hospital Tesanj, Bosnia and Herzegovina \\ ${ }^{2}$ Clinic for Children's Diseases, University Clinical Center Tuzla, Bosnia and Herzegovina
}

Corresponding Author: Hajric Zidan Zlata

\begin{abstract}
We describe iron deficiency and silent intracranial tuberculomas with pulmonary miliary tuberculosis in 13-year old girl which can be rare seen, particularly in immunocompetent children. She presented as respiratory infection with lack of menstrual bleeding. She didn't receive BCG vaccination. Chest roentgenogram showed miliary pattern while MRI of brain revealed parenchymal tuberculomas. Empirical 4 antitubercular drug treatments were initiated. Control showed a decrease in size and number of brain tuberculomas. Silent brain tuberculomas with miliary tuberculosis could be rare seen, particularly in immunocompetent children. It remains an open question whether the irregular menstrual bleeding and iron deficiency was associated with the drop of her immunity and increased risk for military tuberculosis.
\end{abstract}

Key Words: BCG vaccination, irregular menstrual bleeding, MRI of endocranium

\section{INTRODUCTION}

Miliary tuberculosis (TBM) occurs as a result of widespread haematogenous dissemination of the bacilli and with tubercular meningitis is commoner amongst females who were anaemic and hypocalcaemic. ${ }^{1}$ TBM is rare seen in immunocompetent children., Haematogenous spread from the lungs or gastrointestinal tract is most common, leading to small subpial or subependymal infective foci. These are termed Rich and form a reservoir from which intracranial manifestations may arise. ${ }^{4,5,6}$ This can occur either during the primary infection (uncommon, and more frequently seen in children) or be reactivated later and cause a post primary infection. Tuberculosis of central nervous system (CNS) can take a number of forms meningitis or tuberculomas and has predilection for younger patients with different kind of clinical presentation, although in all cases symptoms and signs are non-specific including fever, seizures, meningism and focal neurological deficits. ${ }^{1,7}$. Here we are presenting a case of silent intracranial tuberculoma with miliary tuberculosis in 13year old girl with lack of menstrual bleeding in the past and secondary iron deficiency.

\section{CASE REPORT}

A 13- years old girl had fever, cough and clear nasal secretion for 20 days, with anorexia and lack of menstrual bleeding in the past few months. It looked like respiratory infection and she was treated with antibiotics without improvement. The Chest X-ray revealed a diffuse, micronodular mottling scattered bilateral throughout both lung fields, typical for miliary tuberculosis (Figure 1), which was confirmed by CT imaging. Our patient was third child of the family. There was no history of inherited diseases and no history of tubercular contact. The antenatal history was remarkable. She was born full term in Switzerland where she lived in her early 
childhood. She didn`t received BCG vaccination.

Physical examination revealed astenic constitution, pallor of the skin and hypertrophic tonsils. In lung examination found clear and equal breath sound. Neurological status was normal. A white cell count after admission was normal 7900 leucocytes in a $\mu \mathrm{L}$ of blood. Other findings of patient showed: iron deficiency Fe 2,80 $\mu \mathrm{mol} / \mathrm{L}(6-29.2 \mu \mathrm{mol} / \mathrm{L})$, elevated ferritin level $211 \mu \mathrm{g} / \mathrm{L}(4.5-170 \mu \mathrm{g} / \mathrm{L})$, low count of total iron binding capacity (TIBC) 32,80 $\mu \mathrm{mol} / \mathrm{L} \quad(44.8-80.6 \mu \mathrm{mol} / \mathrm{L})$ and normal count unsaturated iron binding capacity (UIBC) $30 \mu \mathrm{mol} / \mathrm{L} \quad(12.5-55.5 \mu \mathrm{mol} / \mathrm{L})$. Level of haemoglobin $(\mathrm{Hb}) 13.30 \mathrm{~g} / \mathrm{L}(11.8-$ $14.9 \mathrm{~g} / \mathrm{L}$ ), percent of hematocrit (Hct) 43.50 $\%$ (35.4-45), count of red blood cells (RBC) $5.32 \times 10^{6} / \mu \mathrm{L}$, count of platelets (PLT) 257 $000 / \mu \mathrm{L}(178000-420000 / \mu \mathrm{L})$ was normal. $\mathrm{C}$-reactive protein showed increasing trend from admission to 3 weekslater (Table 1). MRI of endocranium showed multiple nodular lesion in brain parenchyma with probably miliary tuberculosis (Figure 1). Clinical meningitis was not developed. Quantiferon TB Gold test was positive 6.55 $\mathrm{IU} / \mathrm{ml}$. In cerebrospinal fluid analysis protein $0.28 \mathrm{~g} / \mathrm{L}$, glucose $3.30 \mathrm{~g} / \mathrm{L}, \mathrm{Cl} 120$ $\mathrm{mmol} / \mathrm{L}$, cell $3 \times 10^{6}$, smear and culture for tuberculosis negative. Smear of feces for tuberculosis in three times were negative, urinocultures and koprocultures were negative as well. Six gastric lavages were performed. Smear for tuberculosis of all six was negative. Two of six cultures were positive for tuberculosis (Mycobacterium tuberculosis was isolated).

Seven days after admission, empirical 4 drug antituberculosis treatment was started with Prednison, hepatoprotectiv, $\mathrm{H} 2$ blocator. Patient was febrile for 18 days after admission. After starting treatment her appetite improved, she gained some weight, her skin colour was better and she had menstrual bleeding again. During hospitalisation her neurological status was normal.
Control $\mathrm{X}$ ray of chest showed improvement, control laboratory and microbiological findings were normal. Smears and cultures for tuberculosis of two control gastric lavages, 2 and 4 weeks after beginning of treatment, were negative. Eighty six days after admission patient was discharged with continuation of treatment. MRI of the brain showed a decrease in size and number of brain tuberculomas at 4 months after treatment.

\section{DISCUSSION}

Meningeal symptoms and signs, except fever in our patient were absent. Anorexia without weight loss was present. There is no history of tubercular contact and BCG vaccination was not received. The most clinically significant form of disseminated tuberculosis is miliary disease, where massive numbers of bacilli are released into the bloodstream, causing disease in 2 or more organs. Tuberculosis of the CNS is the most serious complication in children and is fatal without prompt and appropriate treatment. ${ }^{7}$ Comparing our case with studies of miliary tuberculosis in children done by others, we found that our patient had fever, cough and duration of these symptoms between 15 days and 1 month which is consistent with other cases. Elevated erythrocyte sedimentation ratio ESR, $C$ reactive protein and normal white cell count like in this case are usual laboratory finding. ${ }^{8,9,10}$

Our patient didn't have any of the predisposing or associated conditions described in patients with miliary tuberculosis., ${ }^{2,4}$ But, she had lack of menstrual bleeding in the past few months and iron deficiency possibly anaemia which increased risk of TBM or tubercular meningitis. ${ }^{1}$

In recent studies prevalence of BCG vaccination in children with miliary tuberculosis is from $14.52 \%$ to $88 \% .^{5}$ It appears that it prevents life-threatening forms of tuberculosis in infants and young children. ${ }^{6}$ Our patient did not receive BCG 
Hajric Zidan Zlata et.al. Silent brain tuberculomas with acute miliary tuberculosis in 13-year old girl - case report.

vaccination and that could be one of the reasons for disseminated disease.

A miliary pattern on chest radiograph is not required for diagnosis confirmation, as it is normal in approximately $50 \%$ of patients with a confirmed diagnosis of disseminated TB. ${ }^{7}$ It allows identification of 59 to $69 \%$ of cases of TBM. High resolution computed tomography (HRCT) of the chest is more sensitive for diagnosis of TBM than plain chest radiography. In our case chest radiograph revealed a characteristic finding and that was the main reason we suspected of miliary tuberculosis (Figure 1).

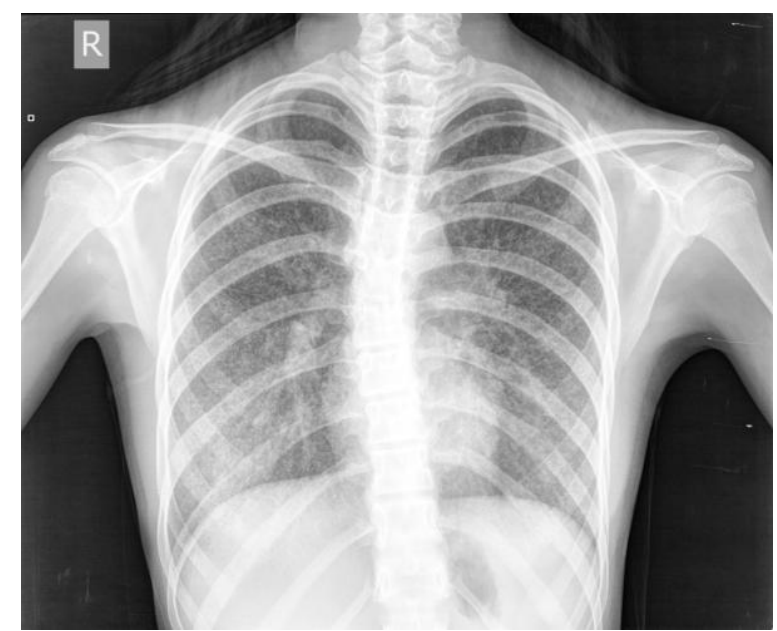

Figure 1: Chest X-ray of patient (before treatment): revealed a diffuse, micronodular mottling scattered bilateral throughout both lung fields

TBM is a fatal disease if not treated. Antituberculosis treatment is the cornerstone of management. Corticosteroid therapy may be beneficial. Empirical treatment for possible but not yet definitive TBM increases the likelihood of survival and should never be withheld while test results are pending. 5

Acknowledgement: None

Conflict of Interest: None

Source of Funding: None

\section{REFERENCES}

1. Kalita J, Misra UK. Tuberculous meningitis with pulmonary miliary tuberculosis: A clinicoradiological study. Neurol India 2004; 194-6.

2. Khan EA, Starke JR. Diagnosis of Tuberculosis in Children: Increased Need for Better Methods. Emerging Infectious Diseases 1995; 1: 115-123.

3. Rehman A, Sheikh MA, Waraich MM, Azam M. Miliary tuberculosis in children. Pediatr Infect Dis J 1991; 10: 832-6.

4. Sharma SK, Mohan A, Sharma A. Challenges in diagnosis and treatment of miliary tuberculosis. Indian $\mathrm{J}$ Med Res 2012; 135: 703-730.

5. Lorber J. Current results in treatment of tuberculous meningitis and miliary tuberculosis. Br Med J 1956; 4974: 100911.

6. Misra UK, Kalita J, Roy AK et al. Role of clinical radiological and neurophysiological changes in predicting the outcome of tuberculous meningitis: An multivariable analysis. J Neurol Neurosurg Psychiat 2000; 68: 300-3.

7. Gee GT, Bazan C, Jinkins JR. Miliary tuberculosis involving the brain: MR findings. AJR Am J Roentgenol 1992; 73: 589-93.

8. Kwong S, Carignan S, Eun-Young Kang et al. Miliary Tuberculosis: Diagnostic Accuracy of Chest Radiography. Chest 1996; 110(2): 339-42.

9. Lim KH, Chong KL. Multiple organ failure and septic shock in disseminated tuberculosis. Singapore Med J.1999; 40: 176-178.

10. Moon MS. Tuberculosis of the spine, Controversies and a new challenge. Spine 1997; 22: 1791-1797.

How to cite this article: Zlata HZ, Amela P, Selma $S$ et.al. Silent brain tuberculomas with acute miliary tuberculosis in 13- year old girl - case report. Int J Health Sci Res. 2021; 11(6): 145-147. DOI: https://doi.org/10.52403/ijhsr.20210621 